\title{
Does it Matter that we do not Agree on the Definition of Poverty? A Comparison of Four Approaches
}

\author{
CATERINA RUGGERI LADERCHI, RUHI SAITH \& FRANCES STEWART*
}

\begin{abstract}
While there is world-wide agreement on poverty reduction as an overriding goal of development policy, there is little agreement on the definition of poverty. Four approaches to the definition and measurement of poverty are reviewed in this paper: the monetary, capability, social exclusion and participatory approaches. The theoretical underpinnings of the various measures and problems of operationalizing them are pointed out. It is argued that each is a construction of reality, involving numerous judgements, which are often not transparent. The different methods have different implications for policy, and also, to the extent that they point to different people as being poor, for targeting. Empirical work in Peru and India shows that there is significant lack of overlap between the methods with, for example, nearly half the population identified as in poverty according to monetary poverty but not in capability poverty, and conversely. This confirms similar findings elsewhere. Hence, the definition of poverty does matter for poverty eradication strategies.
\end{abstract}

\section{Introduction}

The elimination of poverty is a key concern of all those interested in the development of poor countries, and now provides the main justification for promoting economic growth and development. The central objective of the Millennium Goals, agreed by 149 countries at the UN Millennium Summit in New York, is the halving of poverty by 2015 . In official discourse, e.g. by the World Bank and major donors, almost every policy is currently assessed in relation to its impact on poverty, ranging from debt relief to macroeconomic stabilization. ${ }^{1}$ Ironically, while the objective of poverty reduction currently has overwhelming support, particularly among the donor community, there is increasing debate about what this objective means.

To devise policies to reduce poverty effectively, it is important to know at what we are aiming. The current approach to the identification of poverty and to policy

\footnotetext{
${ }^{\star}$ Ruhi Saith and Frances Stewart, Queen Elizabeth House, International Development Centre, University of Oxford, 21 St Giles, Oxford OX1 3LA. Caterina Ruggeri Laderchi, World Bank, Washington, DC, 20433.

This paper derives from research on "Alternative realities? An empirical investigation into alternative concepts of poverty" funded by DFID. We have benefited greatly from comments and suggestions from the other members of our team, Barbara Harriss-White and Susana Franco. For more details on the approaches surveyed here see Ruggeri Laderchi (2000, 2001b) and Saith (2001 a, b). For an overview of the research see Franco et al. (2002). We would like to thank Abusaleh Shariff, Abhilasha Sharma and Rajesh Jaiswal of the NCAER in Delhi, the Academy of Science, Lucknow, Enrique Vásquezh, the Universidad del Pacífico, Instituto Cuanto, Araceli Roldan (CESA) and Francisco Díaz Canseco for help in the empirical work in India and Peru reported on in Section 4 of this paper.
} 
formulation is rather messy: on the one hand, there is acknowledgement of its multidimensionality, combined with a pick and choose approach in advocacy with little consistency across studies. On the other hand, in practice the monetary approach mostly retains its dominance in descriptions and analysis, both nationally and internationally. Clarification of how poverty is defined is extremely important as different definitions imply the use of different indicators for measurement; they may lead to the identification of different individuals and groups as poor and require different policies for poverty reduction. ${ }^{2}$ We illustrate this in this paper by presenting a theoretical and an empirical comparison of different approaches to poverty. We concentrate on four alternative understandings of poverty: the monetary approach, the capabilities approach, social exclusion as defining poverty and the participatory approach.

Different interpretations of reality translate into different poverty measures. These differences, in part, reflect different views of what constitutes a good society and good lives. Our main purpose in this paper is to explore these differences and their implications, rather than assessing their merit. It is our view that clearer and more transparent definitions of poverty are essential prerequisites of any development policy that puts poverty reduction at its centre. Current policy discourse has embraced broad multinational conceptualizations of poverty (e.g. the World Development Report 2000/01). We aim to show that there may be tensions between the different dimensions considered, and that clarity is needed in understanding where these tensions lie and how such multidimensionality can be translated into measurement.

Some issues common to any approach to the definition and measurement of poverty are discussed in Section 2. This is followed by a theoretical comparison of the four approaches (Section 3). Section 4 briefly presents some empirical findings on the extent to which the differences matter in practice. Section 5 reflects on some implications of the findings.

\section{Common Problems Encountered in Defining and Measuring Poverty}

A number of general questions about how to define and measure poverty apply to all approaches, many of which were already apparent in the pioneering work of Rowntree in the late 19 th and early 20 th centuries. It is helpful to discuss these in general terms before a detailed discussion of different approaches.

Firstly, a fundamental issue-which underlies the differences in the approaches we are considering - is the space in which deprivation or poverty is defined and how that space is captured by the indicators chosen. Different poverty definitions span different "spheres of concerns", not all of which may be easily measured. For example, should the definition of poverty be confined to material aspects of life, or include social, cultural and political aspects? Is poverty to be measured in the space of utility or resources (broadly adopted by different versions of the monetary approach) or in terms of the freedom to live the life one values (as in the capabilities approach)? And for any approach what type of indicators should be used? For example, should indicators capture what may be achieved, given the resources available and the prevailing environment - that is, the ability to be and do a variety of things - or what is actually achieved by individuals?

Secondly, there is the question of the universality of the definition of poverty. Should we expect definitions and measurement indicators applied in one type of society to be transferable to other societies without serious modifications, or even at all? Two of the approaches we consider (the monetary approach and social exclusion) were initially devised for developed countries. In each, there are problems in translating their 
application to developing countries: in the monetary approach, for example, this involves heroic imputations of values for subsistence production; in social exclusion, substantial differences in societal norms lead to major differences in the defining characteristics of social exclusion. ${ }^{3}$ In contrast, the capabilities approach and participatory methods were first devised with developing countries in mind, and the reverse question applies. Here again it is clear that the interpretation of the approaches will differ between societies with radically different characteristics - this is not just a matter of developed versus developing countries, but also other major societal differences (e.g. between socialist and capitalist societies). To some extent methods are context-specific, and may need to be reinterpreted for particular societies for operationalization, which can make comparisons across contexts problematic.

Thirdly, there is the question of whether methods are "objective" or "subjective". Most statements about poverty suggest objectivity, i.e. it is implied that there is a certain reality "out there" which poverty statistics capture. To the extent that value judgements affect measurement, the methods are not objective, and the question then is who is making the value judgements: are they made implicitly by the researchers or statisticians who are measuring poverty? Are they made explicitly, and subject to sensitivity analysis, so that the effects of those value judgements can readily be evaluated? To what extent are they understood and shared by other stakeholders, for example, through the political process or through a participatory process involving the poor themselves?

Fourthly, a crucial question is how to discriminate the poor from the non-poor through the use of poverty lines. Two related issues arise: firstly, what is the justification for adopting any such line; and secondly, to what extent is the poverty line defined as relative to a given context or is intended to reflect some absolute standards of deprivation.

At a theoretical level, the choice of a definition of poverty relies on the crucial assumption that there is some form of discontinuity between the poor and the non-poor that can be reflected in the poverty line. Such a break can pertain to the behaviour of the poor, or to some salient feature that identifies the poor and that either moral or political considerations suggest should be addressed. For example, one approach, justified on political or moral grounds, is to define the poverty line at a level at which people can realize a full or decent life. Essentially, rights based approaches to poverty do this and similar concerns animate the capability approaches (e.g. Nussbaum, 2000). Expenditure requirements to ensure minimal nutrition is generally taken to be the fundamental break in the monetary approach (see below). Other types of "natural" breaks can be found: for example, evidence on the importance of social networks for provision of informal insurance and support mechanisms, as well as from participatory research, suggests there is a "break" at levels of resources below which people are considered unworthy of community support as they would not be able to reciprocate their obligations if needed (see, e.g. Howard \& Millard, 1997).

Considerable attention has been devoted to the issue of whether the threshold between the poor and non-poor should be sensitive to the characteristics of the overall population. At one extreme, the poverty line between poor and non-poor is defined with reference to some summary measure of the overall distribution (as in the case of the member states of the European Union, where the poverty line is set at $60 \%$ of the median of "equivalized" income). At the other extreme, a poverty line is set in terms of minimal requirements in the dimension of interest identified in absolute terms, e.g. on the basis of some needs of the individual deemed as essential for survival.

In reality it is difficult, perhaps impossible, to identify such absolute needs irrespec- 
tive of societal standards. For example, in the era before the advent of writing, literacy could not be identified as an absolute requirement, yet now any definition of capability poverty would include this dimension. Further, most apparently "absolute" indicators of poverty contain some relative element, reflecting the need to maintain the relevance of a given definition over time. For example, although he did not take an explicitly relative approach in his second study of York in the 1930s, Rowntree updated his minimum requirements for people to be non-poor to include having a bath and a garden. Sen has pointed out that even if requirements can be set as absolute in terms of needs anchored to some standards with intrinsic value, they would generally need to be interpreted as relative in terms of resources. For example, if poverty is defined in absolute terms in relation to nutritional requirements, it is likely to some extent to be relative in income terms, since in richer societies people generally need more money to acquire the same nutrition-as cheaper foods are not available, transport is needed to shop, and so on.

None the less, a conceptual difference remains in the choice along the continuum between an overtly relative approach and an intended absolute approach. This choice is ultimately a matter of political and cultural sensitivity. From a political point of view, a relative standard makes sense as people's toleration of poverty and governments' willingness to take action against it is generally relative to average standards in that society. It is also true that the sense of deprivation or unhappiness caused by poverty is greatly influenced by average societal standards. In general, relative standards are mostly adopted in countries where it is assumed that all have access to the means to ensure survival, while where the availability of a survival minimum is felt as a pressing issue (i.e. generally in developing countries), absolute standards are more often adopted.

A fifth issue concerns the unit over which poverty is defined-this is partly a question of whether poverty is defined at the level of the individual or the family, and also a matter of the geographical unit of analysis. While it is individuals who suffer or enjoy their lives, data, particularly of a monetary kind, normally pertain to households, and some resources (not only money income, but also sanitation, clean water) come via the household and it is difficult to ascertain the distribution of services they provide to the individual. The geographic unit matters in three ways: firstly, for identifying the society with respect to which the relative poverty lines are drawn; secondly, for defining the boundaries of the relevant market, for example, to obtain prices for valuations; and thirdly, in terms of targeting, since when geographic areas are used for targeting, how the areas are defined will affect the efficiency of targeting.

Sixthly, a pervasive question is how to deal with multidimensionality: considering that individual well-being (and lack of it) manifests itself in multiple dimensions, should an aggregate index be developed, and how? The issue can be bypassed in a monetary approach by assuming that the monetary metrics either captures the essence of deprivation, or proxies all other deprivations. The proxying role of the monetary measures is reinforced to the extent that relevant heterogeneity between individuals can be adjusted for, ${ }^{4}$ so that their monetary resources become comparable across individuals. The other approaches, however, incorporate what Sen labels the constitutive plurality of a welfare assessment and therefore do not present themselves in the form of a single index. These approaches raise two questions: how each constituent dimension is to be measured and how they are to be aggregated. Any aggregation requires a decision on whether and how the severity of deprivation in each of the basic dimensions should be included. Aggregation is helpful to summarize societal deprivation. However, in general there is no right way of aggregating. By definition 
aggregation implies a loss of information, whose influence on the final results should be appropriately tested for.

Seventhly, the time horizon over which poverty is identified needs to be defined. This is commonly viewed as a technical issue concerning the period of time over which poverty should be measured, i.e. over a month, a year, or longer time. Many people move in and out of poverty over seasons and years, therefore the longer the time perspective the less poverty will appear. Such variations are less likely the more the poor have access to income- and consumption-smoothing strategies (Morduch, 1995), which suggests that in such cases there is a case for adopting longer time periods to arrive at less noisy accounts of living standards. Yet, these fluctuations can be of particular interest if they entail far-reaching consequences for the most vulnerable individuals (consider childhood poverty's consequences for future physical and cognitive development). If poor households are credit and insurance constrained, therefore, there is a case for shorter time periods that allow a greater differentiation between the chronic poor (variously defined as those always below a poverty line, or those, on average, below a poverty line; Hulme \& Shepherd, 2003) and the transitory poor. These considerations, however, do not apply to all approaches equally, as some capability and social exclusion measures, though observed at one point in time, by their nature indicate long-term deprivation either because they have long-term consequences (e.g. child malnutrition as revealed by low height for age) or because they are structural (e.g. some correlate of social exclusion, such as race).

Another aspect of the time horizon chosen relates to the concept of lifetime poverty. This could be seen as a statistical question concerning which and how many individuals are chronically poor throughout their lives. But it could also be approached in terms of life-decisions: what critical decisions or circumstances in a person's life-pre-birth, in their early childhood, in their school years, as an adult, for example-led to lifetime poverty (or avoided it). This approach could be useful for causal and policy analysis.

Finally, there is a general question about the extent to which a definition of poverty offers (or should offer) a causal explanation for poverty and points to policies towards its alleviation. Some of the approaches are built on causal analysis, while others aim only at providing a description. We believe, however, that even such descriptive exercises influence the broad thrust of policy-making. We shall return to this issue in the concluding section.

\section{An overview of the four approaches}

\subsection{The Monetary Approach}

As noted, the monetary approach to the identification and measurement of poverty is the most commonly used. It identifies poverty with a shortfall in consumption (or income) from some poverty line. The valuation of the different components of income or consumption is done at market prices, which requires identification of the relevant market and the imputation of monetary values for those items that are not valued through the market (such as subsistence production and, in principle, public goods) (Grosh \& Glewwe, 2000). The assumptions needed for such imputation are generally somewhat heroic. The key assumption of this way of proceeding is that, with appropriately devised tools, uniform monetary metrics can take into account all the relevant heterogeneity across individuals and their situations.

For economists, the appeal of the monetary approach lies in its being compatible with the utility maximizing behaviour assumption that underpins microeconomics, i.e. 
that the objective of consumers is to maximize utility and that expenditures reflect the marginal value or utility people place on commodities. Welfare can then be measured as the total consumption enjoyed, proxied by either expenditure or income data, and poverty is defined as a shortfall below some minimum level of resources, which is termed the poverty line.

The validity of the approach then depends in part on:

- whether utility is an adequate definition of well-being;

- whether monetary expenditure is a satisfactory measure of utility; ${ }^{5}$

- whether a shortfall in utility encompasses all we mean by poverty;

- the justification for a particular poverty line.

The use of a monetary approach to poverty can, however, be justified in two quite different ways. Firstly, the minimum rights approach, where a certain basic income is regarded as a right without reference to utility but rather for the freedom of choice it provides (Atkinson, 1989; van Parijs, 1992). This view has not gained much following and faces much the same problems as the welfare-based view, for example in determining the level of basic income to be chosen as a universal right. Secondly, the use of a monetary indicator is often invoked not because monetary resources measure utility, but because it is assumed it can appropriately proxy other aspects of welfare and poverty. In this view, while lack of resources does not exhaust the definition of poverty, monetary indicators represent a convenient short-cut method, based on data that are widely available, to identify those who are poor in many fundamental dimensions, not only lack of resources but also nutrition, health, etc. Empirical investigations are needed to explore the validity of this assumption (see Section 4).

3.1.1 Historical antecedents. The monetary approach to poverty measurement was pioneered by the seminal work by Booth and Rowntree, who studied poverty in London and York, respectively, in the 19th and early 20th Centuries.

Booth's study of the East End of London, in 1887, was prompted by widespread rioting by the poor, which socialists explained at the time by the claim that one-third of the population was poor. This was a much higher proportion than the rate of poverty defined as those in receipt of poor-relief, which amounted to about 5\% (Booth, 1887). Booth used informants (school board visitors) rather than direct enquiry among the poor. He categorized people into eight social classes, four of which represented different degrees of poverty. His classification went beyond a pure monetary identification of the poor, encompassing more sociological concerns such as the "conditions attaining in the home, and the nature and regularity of employment" (Marshall, 1981, p. 145).

Explicitly following in Booth's footsteps though adopting a different methodology, Rowntree's (1902) work has been described as the first scientific study of poverty. Rowntree defined a poverty line by estimating monetary requirements for a nutritionally adequate diet together with needs for clothing and rent. Those below this line were defined as being in primary poverty. The interviewers also classified households who were seen to be living in "obvious want and squalor": those who fell into this category despite being above the defined poverty line were classified as being in secondary poverty. On the basis of interviews of people around York, Rowntree identified 30\% of the population as in poverty.

Both Booth and Rowntree agreed on some important issues-views that are shared by most economists adopting a monetary approach today. Firstly, they believed their assessment was abjective one, i.e. that an objective condition termed poverty existed, 
which they were measuring. Secondly, their assessment was an external one, i.e. carried out by social scientists and others, not by the poor themselves. Thirdly, they took an individualistic view of poverty, i.e. that poverty should be defined with respect to individual circumstances and behaviour, rather than as a social phenomenon. These three elements remain central to the current practice of the monetary approach.

3.1.2 Some outstanding issues concerning definition and measurement of monetary poverty. As noted, the modern monetary approach contains many elements already present in those early analyses, especially Rowntree's method of identifying the poverty line. None the less, there have been many methodological advances in the development and standardization of this approach to measurement (e.g. Grosh \& Glewwe, 2000), although some issues remain contentious, leading to theoretical and methodological choices that undermine the claims of objectivity of this approach.

The welfare indicator. Monetary poverty is arguably better measured by consumption data as it approximates welfare more closely than income (Deaton, 1997). It also comes closer to a measure of long-term income, avoiding some of the short-term fluctuations in income and access to resources - under the assumption, of course, that individuals have access to credit and saving instruments. On the basis of a minimum rights perspective, however, a case has been made for the use of income (Atkinson, 1989). It is theoretically possible to incorporate measures of non-marketed goods and services in estimates of either consumption (which is approximated by expenditure data, sometimes with adjustments for the use of services from durables) or income. In practice, however, these measures almost invariably include only private resources, and omit social income (i.e. a variety of goods and services provided publicly, e.g. schools, clinics, the environment). This can lead to an implicit bias in policy choices in favour of the generation of private income as against public goods provision, and similarly, a bias in the identification of the poor for targeting purposes towards those lacking private income.

The monetary poverty line. A key issue-noted earlier-is how to differentiate the poor and non-poor, and whether there is an objective way of doing so. In the case of the monetary approach, various technical solutions have been suggested for this differentiation, notwithstanding the fuzziness of the theoretical framework that underlies it. At a fundamental level, in fact, problems in identifying a poverty line stem from the fact that there is no theory of poverty that would clearly differentiate the poor from the non-poor.

Relative poverty lines can be determined by political consensus. In fact, in many developed countries, a pragmatic way of determining the poverty line is to define those deprived as those who receive support from public sources. Atkinson has written extensively against this practice in the UK, pointing out that considering the poor as those who are entitled to social security benefits leaves this identification at the mercy of budgetary decisions. ${ }^{6}$

Attempts to find an objective basis for an absolute poverty line aim at identifying behavioural breaks between the poor and non-poor. Issues of the nutritional needs for survival, and/or efficiency wages, provide the most common basis for such a break. For example, Lewis \& Ulph (1998) suggest a model where a discontinuity between the poor and non-poor could be identified from behaviour where: (i) minimum positive 
expenditure is needed on one or more items to escape poverty; and (ii) this minimum provides indirect benefits for participation in other activities, which could be work (reverting to efficiency wages types of arguments), or could be survival. An efficiency wage argument has been made by Dasgupta (1993) and others. Yet there is considerable ambiguity about what constitutes an efficiency wage, questions about whether this should be applied to those outside the workforce (e.g. the old or disabled) and it also raises the moral question of the appropriateness of defining poverty in such an instrumental way.

Ravallion (1998) has suggested that the poverty line should be defined as the "minimum cost of the poverty level of utility". Yet this does not get one much further as the concept of a "minimum level of utility" is itself not well-defined. More emphasis is given to the methodological (rather than the theoretical) issue of how to calculate this minimum. Ravallion suggests two methods for approaching this issue: one is the food energy intake method, which essentially amounts to a nutritionally-based poverty line; the other is a "cost of basic needs" line, either starting with food and adding a non-food component (a method similar to Rowntree's), or starting with a list of basic needs (which of course themselves need to be defined) and costing them.

For the most part, nutritional requirements form the fundamental justification of, and practical basis for, defining the poverty line in the monetary approach. Yet there are problems about nutritionally-based poverty lines. Differing metabolic rates, activities, size, gender and age among people mean that what is adequate varies among them (Sukhatme, 1982, 1989; Dasgupta, 1993; Payne, 1993). Then differing tastes, food availability and prices affect how much money income is needed to secure any particular level of nutrition. Moreover, poverty lines are often drawn up at the level of the household, yet the way resources are distributed within the household affects the nutrition levels of individuals within it (see later). All this suggests that it is not possible to draw up a unique poverty line based on nutritional requirements, but rather a range of income, from a minimum line below which everyone is certainly in poverty (Figure 1 ), to a line above which no one would be in poverty, in nutritional terms. Such a practice is akin to the fairly common approach of adopting two poverty lines, identifying "poverty" and "extreme poverty". Lipton (1988) has argued that there is a natural break in behaviour justifying a distinction between what he calls "the poor" and the "ultra-poor", defining the latter as households spending at least $80 \%$ of their income on food, yet receiving less than $80 \%$ of their calorie requirements. He argues that empirical work identifies $80 \%$ as a maximum that people can spend on food because of other essential needs. However, others have questioned whether the $80 \% / 80 \%$ lines hold, and whether there is such a natural break that is universally valid (Anand et al., 1993). Others have used household perceptions to differentiate poverty and core poverty (see Clark \& Qizilbash, 2002). ${ }^{7}$ 


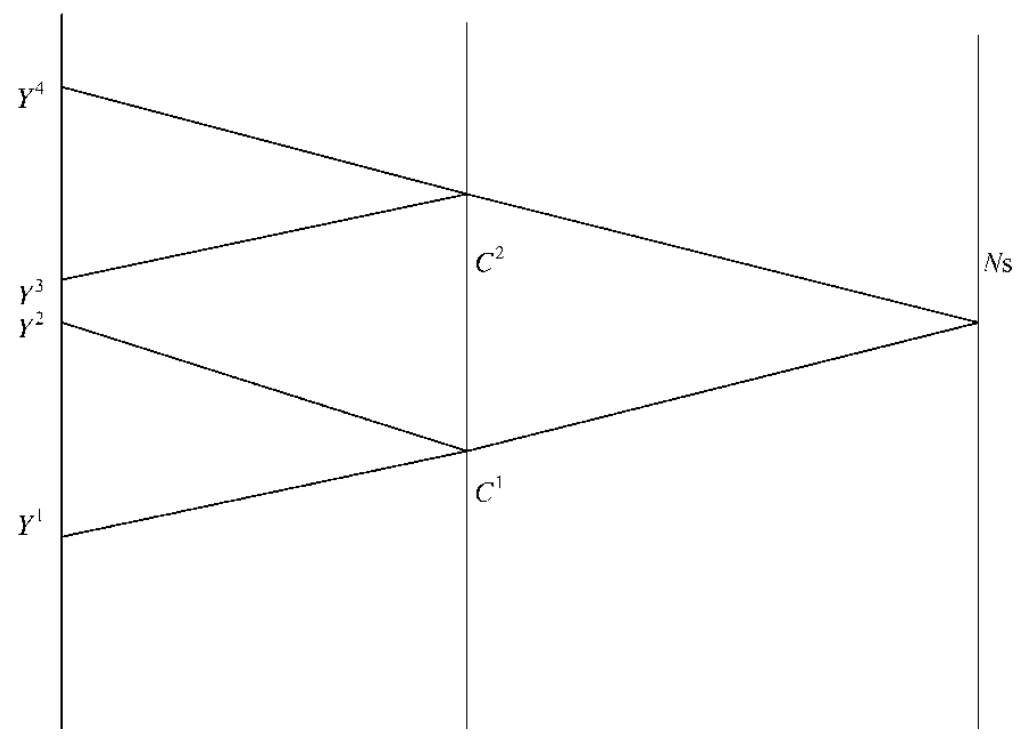

Figure 1. Monetary poverty: a range.

Let $N_{\mathrm{s}}$ be a minimum "adequate" nutrition level for any individual. $C^{1}, C^{2}$ is the range of calories that may be needed to achieve this nutrition level, which varies among individuals according to metabolic rate, age, gender and activity. In order to achieve calorie consumption for an individual, $C^{1}$, household income of from $Y^{1}$ to $Y^{2}$ may be needed, varying according to numbers in the household, and household consumption and allocation patterns. For calorie consumption, $C^{2}$, household income of between $Y^{3}$ and $Y^{4}$ may be needed. Below household income $Y^{1}$, malnutrition is certain; above household income $Y^{4}$, adequate nutrition is certain.

Individuals versus households. Economists' approach to welfare is essentially individualistic, i.e. welfare pertains to individuals, hence poverty (as a welfare shortfall) is a characteristic of individuals too. Income and consumption data, however, are normally collected by household, so that some adjustment is needed in translating household resources into individual poverty. Such an adjustment has three aspects: one is to estimate the needs of different individuals; the second is to estimate the extent of economies of scale enjoyed; and the third is to consider how household resources are allocated to the different individuals within the household.

The issue of estimating individual resource needs involves both theoretical and practical problems. If a minimum rights perspective is adopted and all individuals have the same rights, then it would be wrong to weight individual needs differently. However, if those rights are seen as relating not to resources but to outcomes (e.g. the right to a certain standard of living, or the right to certain achievements in terms of nutrition), or, alternatively, adopting a utility-based perspective, adjustments that take different individual characteristics into account are justified.

In order to take into account both differences in needs and economies of scale in consumption, equivalence scales (defined as the "ratio of the cost (to a household) of achieving some particular standard of living, given its demographic composition, to the cost of a 'reference' household achieving that same standard of living") can be used 
(Banks \& Johnson, 1993). Though this definition of equivalence scales assumes that they can be calculated by reference to observed behaviour, in practice there are considerable variations in the estimates, which are sensitive to the specific methods adopted. It should be noted that equivalence scale calculations are typically based on patterns of consumption of the "average" household, and do not fully take into account power or bargaining considerations which appear to play a role in the way resources are allocated within the household.

The importance of various adjustments for the empirical estimation of poverty has recently been illustrated powerfully by Szekely et al. (2000), who have shown that the poverty rate varies between 13 and $66 \%$ of the population in 17 Latin American countries, according to the methods adopted towards calculating equivalence scales, assumptions about the existence of economies of scale in household consumption, methods for treating missing or zero incomes and adjustments to handle misreporting. Given the magnitude of this variance, adopting stochastic dominance techniques (Atkinson \& Bourguignon, 1987) to test the robustness of poverty estimates to varying assumptions on where the poverty line is set or how differences in needs are taken into account, as suggested by Lipton \& Ravallion (1993), would indicate that many monetary estimates of poverty are not robust.

Aggregation issues. The issue of how to translate the identification of poverty at an individual level into an aggregate value is linked closely to the literature on social valuation. Following Sen's (1976) pioneering contribution, which applied a similar approach to poverty measurement to that used in the measurement of inequality, the literature generally adopts an axiomatic approach to setting the desirable properties of a poverty index. Foster, Greer and Thorbecke (FGT) (1984) is a fundamental contribution offering a general formulation ${ }^{8}$ including a valuation parameter of choice, alpha, which incorporates some of the most widely used indices. ${ }^{9}$

It has become standard practice to compute FGT indices for values of alpha ranging from 0 to 2 in order to test the sensitivity of the poverty assessment to the distribution of resources among the poor.

\subsubsection{Some conclusions on the monetary approach.}

- At a theoretical level it has been shown that different theoretical interpretations underpin the approach. All of them have their weaknesses. The welfarist view, for example, assumes that all relevant heterogeneity between individuals can be controlled for, but this requires rather strong assumptions. Further, this approach disregards social resources that are of great importance in determining individual achievements in some fundamental dimensions of human well-being such as health and nutrition. The alternative rights-based approach also fails to capture effective achievements in terms of human lives.

- While the monetary approach has benefited from significant methodological developments in terms of measurement, these technical adjustments require numerous value judgements. Despite their apparent "scientificity", the estimates of poverty the approach provides, therefore, are open to question-an example is the recent debate on the one dollar a day poverty line (Reddy \& Pogge, 2002; Ravallion, 2002). It should be noted that while many of the methodological elements, which are part of a monetary poverty assessment, are derived from economic theory (e.g. the literature on equivalence scales), poverty in itself is not an economic category. Though efforts 
have been made to identify natural breaks between poor and non-poor based on some behavioural characteristics, none are fully satisfactory in pointing to a unique poverty line.

- It has also been emphasized that this approach is fundamentally addressed to individual achievements; social interactions and interdependencies are considered only from the mechanical point of view of appropriately scaling household resources to take into account different household structures.

- The value judgements that form an intrinsic aspect of much of the methodology-for example, about what should constitute an essential consumption basket-like many other aspects of the methodology, are generally performed "externally", i.e. without the involvement of poor people themselves.

The three other approaches to deprivation reviewed in this paper address some of the perceived defects of the monetary approach.

\subsection{The Capability Approach}

According to Sen (1985, 1997, 1999), who pioneered this approach, development should be seen as the expansion of human capabilities, not the maximization of utility or its proxy, money income. The capability approach (CA) rejects monetary income as its measure of well-being, and instead focuses on indicators of the freedom to live a "valued" life. In this framework, poverty is defined as deprivation in the space of CA, or failure to achieve certain minimal or basic capabilities, where "basic capabilities" are "the ability to satisfy certain crucially important functionings up to certain minimally adequate levels" (Sen, 1993, p. 41).

The CA constitutes an alternative way of conceptualizing individual behaviour, assessing well-being and identifying policy objectives, based on the rejection of utilitarianism as the measure of welfare and of utility maximization as a behavioural assumption (Sen, 1993). It is rooted in a critique of the ethical foundations of utilitarianism. It is argued that the only defensible basis for a utilitarian approach is to ground it in a concept of utility interpreted as "desire fulfilment". ${ }^{10}$ This implies letting individuals" mental disposition play a critical role in social evaluation while neglecting aspects such as their physical condition which influence their quality of life. As a result, people can be "satisfied" with what is a very deprived state (e.g. ill-health, termed "physical condition neglect"), while their desires are constrained by what seems possible (described as "valuation neglect"). Furthermore, choices are influenced by the social context not only in terms of its influence on expectations, but also through strategic interactions, making observed behaviour in the market of dubious value for social valuation (Sen, 1985).

In the CA approach well-being is seen as the freedom of individuals to live lives that are valued (termed the capability of the individual), i.e. the realization of human potential. This emphasis on the "outcomes" characterizing the quality of life of individuals implies a shift away from monetary indicators (which at best can represent indirect measures of those outcomes) and a focus on non-monetary indicators for evaluating well-being or deprivation. Monetary resources are considered only as a means of enhancing well-being, rather than the outcome of interest. Monetary resources may not be a reliable indicator of capability outcomes because of differences individuals face in transforming resources into valuable achievements (functionings), differences which depend on individual characteristics (e.g. differences between individuals in terms of metabolic rates; differences between able bodied and handicapped 
individuals) or differences in the contexts individuals live in (e.g. differences between living in areas where basic public services are provided and areas where such services are absent). If the emphasis is on final outcomes, poverty (and more generally wellbeing) assessments should take into account the fact that some people need more resources than others to obtain the same achievements. The emphasis is therefore put on the idea of adequacy of monetary and other resources for the achievement of certain capabilities rather than their sufficiency, and the roles of externalities and social goods are brought into the picture as other influences over capabilities.

The instrumental role of monetary resources in the achievement of well-being is illustrated in Figure 2. With their income individuals acquire commodities and the utilization of these commodities' characteristics and those of publicly provided goods and services allows individuals to achieve certain functionings. Besides private monetary income and publicly provided goods and services, an individual's own personal characteristics (including, e.g. age, gender, physical capacities) and the general environmental context help determine the capability set of the individual and the use made of this set, or the individual's functionings. Monetary resources, therefore, remain instrumentally related to the achievement of well-being (or, conversely, poverty), but do not exhaust the causal chain.

3.2.1 Operational issues in measuring poverty as capability failure. Translating the capability approach into an operational framework for poverty evaluation requires one to deal with several issues. Most fundamental is the definition of basic capabilities and of the levels of achievement that are to be considered essential.

Defining basic capabilities. In his work Sen does not provide a specific list of minimally essential CA (though he suggests that basic concerns such as being wellnourished, avoiding preventable morbidity, etc. should be part of such a list) or guidelines for drawing up a universal list. Alkire (2002) has argued that the lack of specification was deliberate in order to allow room for choice across societies and ensure the relevance of the approach to different persons and cultures.

The problem of identification of basic CA is similar to that of the identification of basic needs (BN). ${ }^{11}$ Doyal \& Gough (1991) attempted to define an objective and non-culturally sensitive list of $\mathrm{BN}$ using avoiding serious harm as a fundamental criterion. They include physical health and autonomy (which covers a person's level of understanding, mental health and a range of opportunities) as BN. Satisfiers to achieve these needs, or the actual goods and services required, are argued to vary across societies. Several attempts have been made specifically to define basic capabilities. The most influential is Nussbaum's, who has argued that there is an "overlapping consensus" between different societies on the conception of a human being and what is needed to be fully human. She hopes to arrive at a theory that is not "the mere projection of local preferences but is fully international and a basis for cross-cultural attunement" (Nussbaum, 2000, p. 74).

As can be seen from Table 1, Nussbaum's list represents a western late-20th Century conception of the "good life", raising doubts on its ability to reflect an "overlapping consensus". Moreover, Nussbaum's list defines characteristics of a full human life at a very general level, and does not specify cut-off points for defining deprivation. Other attempts to define the essential capabilities have been conducted by Alkire (2002), Desai (1995) and Qizilbash (1998). Each arrives at similar lists. These lists, and practical applications of the CA approach, e.g. by Drèze \& Sen (1995), 


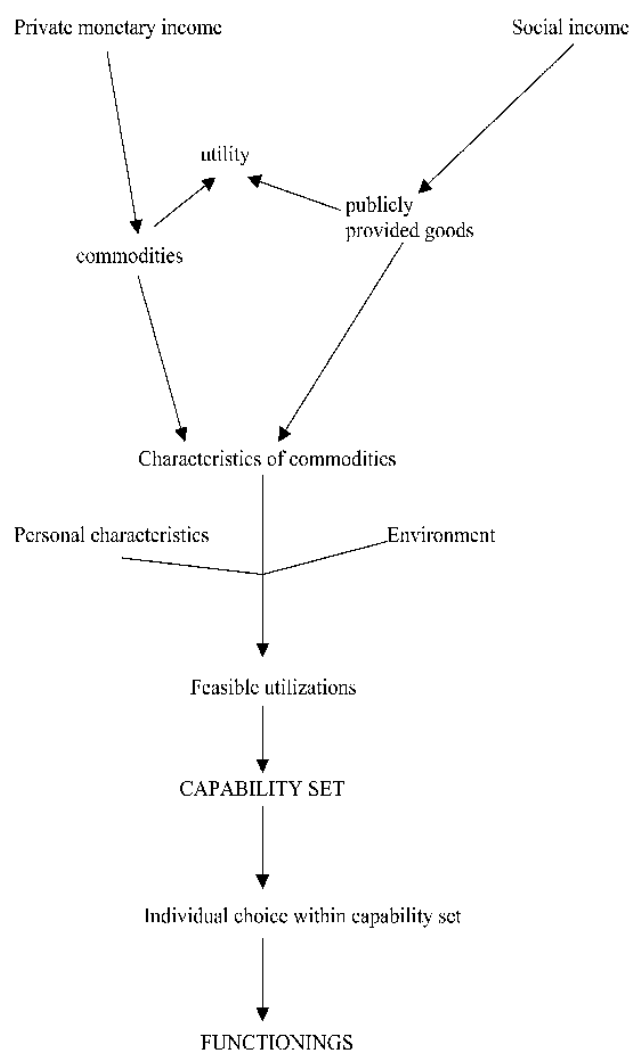

Figure 2. Capability approach-the links.

generally interpret the minimal essential CA as being constituted by health, nutrition and education - broadly the same as the list of basic needs identified in BN approaches (see, e.g. Stewart (1985) and Streeten et al. (1981). Stewart (1995) further explores the differences between $\mathrm{BN}$ and $\mathrm{CA}$ ).

Measurement of capabilities. A second issue in making a CA approach to poverty operational is the translation of the concept of capabilities (i.e. all the possible achievements an individual may have, which together constitute the capability set) into something measurable. The crucial issue is, of course, that capabilities represent a set of potential outcomes and as such are difficult to identify empirically. Arguably, however, if the capabilities considered are basic enough individuals will not be willing to forego them so that assessing their actual achievements, or functionings, should reveal the constraints they face. The identification of the capability set with the set of achieved functionings can be conceptualized as performing the evaluation of a set through one of its elements, in much the same way as economists value budget sets by considering the bundle of goods chosen (Sen \& Foster, 1997); but this risks losing the key insight of the CA, which is its emphasis on freedom. ${ }^{12}$ In practice, there has been a strong tendency to measure functionings rather than capabilities (i.e. life expectancy, morbidity, literacy, nutrition levels) in both micro and macro assessments. Using functionings makes the approach virtually identical with the $\mathrm{BN}$ approach in the measurement of poverty. 
Table 1. Nussbaum's list of features essential to full human life

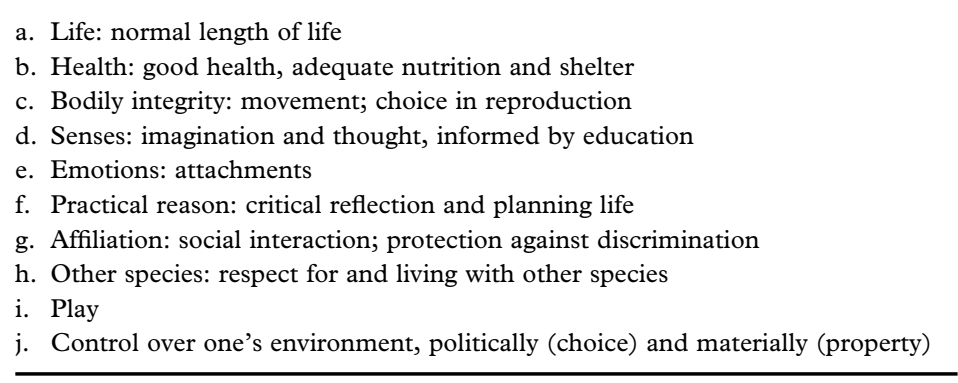

Source: Nussbaum (2000).

The poverty line. As in the other approaches, there is a need to identify breaks in the distribution of capabilities, to differentiate the poor and non-poor. The choice of such breaks - which is necessary for each CA separately-appears to be context-dependent and somewhat arbitrary. The human poverty index developed by UNDP can be taken as an example since the concept of "human poverty" was primarily derived from the CA approach. UNDP defined human poverty as "... deprivation in three essential elements of human life ... longevity, knowledge and decent standard of living ..." (UNDP, 1997, p. 18). The indicators adopted in the 2001 Human Development Report for the three elements were: having less than 40 years life expectancy at birth; adult illiteracy; and an average of not using improved water sources and under five mortality. It is clear that both choice of dimensions and cut-off standards are arbitrary and are likely to be revised according to the general standards attained in the world, the region, or the country where poverty assessments are being made. This is exemplified by the fact that UNDP adopted a different human poverty index for developed countries that includes life expectancy of below 60, lack of functional literacy among adults, the long-term unemployment rate and the population below an income poverty line of $50 \%$ of median disposable household income in the country being assessed. ${ }^{13}$ Whether a universal conception of poverty from a CA perspective can be reconciled with changing measures has not been much discussed (Ruggeri Laderchi, 2001a).

Aggregation. The multidimensional emphasis of the capability framework makes the issue of aggregation particularly pertinent. It is arguable that since each of the different capabilities is intrinsically valuable, no trade-offs between achievements in one or other dimensions should be introduced. This severely limits the type of aggregative strategies that can be adopted. ${ }^{14}$ Yet, aggregation can be desirable for political purposes and to reduce a large amount of information to manageable proportions (e.g. for inter-country comparisons). For policy purposes, fully aggregative strategies (i.e. those which arrive at full orderings by providing explicit trade-offs in terms of achievement in each dimension) are likely to be more useful than strategies that arrive at only partial ones (consider the case of having to identify regions to be given priority for poverty alleviation expenditure). Such fully aggregative strategies include, for example, the use of factor analysis to obtain data-driven weights in aggregating deprivations, the use of fuzzy sets applications, Borda rankings or the more familiar averages (popularized by the work done by UNDP in constructing its human development and human poverty indices), to quote those methods that have been commonly used in a CA context. Using the concepts of union (a comprehensive approach, by which an individual 
deprived in any dimension is considered poor) or intersection (an overlapping approach, by which only individuals deprived in all dimensions are considered to be poor) are also possible approaches to aggregation. ${ }^{15}$

A further issue is whether and how the severity of deprivation in each of the basic dimensions should form part of the aggregation procedures. Bourguignon \& Chakravarty (forthcoming), for example, provide a formula that allows for varying rates of trade-off across dimensions. Individuals' deprivations in each dimension can be weighted by the distance from each cut-off line, for example, differentiating and giving more weight to the extremely malnourished as against the malnourished.

3.2.2 Some conclusions on the capability approach. The CA approach represents a major contribution to poverty analysis because it provides a coherent framework for defining poverty in the context of the lives people live and the freedoms they enjoy. This approach draws attention to a much wider range of causes of poverty and options for policies than the monetary approach. The shift from the private resources to which individuals have access to the type of life they can lead addresses the neglect of social goods in the monetary approach and its narrow vision of human well-being. Yet, like the monetary approach, arriving at operational measures poses a number of methodological choices. Though decisions on these are also somewhat arbitrary, the choices made are arguably more visible, and therefore more easily subject to scrutiny than in the monetary approach.

There are some features common to the CA and monetary approaches. Firstly, in principle both approaches take an individualistic perspective since both utility deprivation and capability failure are characteristics of individuals, even though, in both cases, communities and households are important determinants of achievements, especially for children and the old. Secondly, both typically represent external assessments, though, in principle, as we shall suggest later, both could be adapted to include more internal inputs. Thirdly, neither approach captures fundamental causes or dynamics of poverty. Fourthly, they aim to describe the situation at a point in time, providing data for, but not themselves directly involving, fundamental analysis of the causes of poverty, although some studies, of course, do follow up measurement with investigations of the causes of, or processes leading to, monetary and/or capability poverty (Dhatt \& Ravallion, 1998; Baker, 1997). Social exclusion and participatory approaches both differ from the monetary and capability approaches in each of these respects.

\subsection{Social Exclusion}

The concept of social exclusion (SE) was developed in industrialized countries to describe the processes of marginalization and deprivation that can arise even in rich countries with comprehensive welfare provisions. ${ }^{16}$ It was a reminder of the multiple faces of deprivation in an affluent society. The concept now forms a central aspect of EU social policy; several European Council decisions (starting with one at the Lisbon Council of March 2000) have adopted strategic goals and political processes aimed at countering the risk of poverty and SE. The concept of SE has been gradually extended to developing countries through the activities of various UN agencies (especially the International Labour Institute) and the Social Summit (Clert, 1999).

The EU defines SE as a: "process through which individuals or groups are wholly or partially excluded from full participation in the society in which they live" (European 
Foundation, 1995). This echoes the earlier work of Townsend, who defined deprivation as referring to people who "are in effect excluded from ordinary living patterns, customs and activities" (Townsend, 1979, p. 31, our italics). More precisely, Le Grand has defined SE as occurring when a person is excluded if he/she is: (a) resident in society; (b) but for reasons beyond his/her control cannot participate in normal activities of citizens in that society; (c) would like to do so. ${ }^{17}$ Others have argued that a person is excluded if conditions (a) and (b) hold, whether or not they actually desire to participate (Barry, 1998).

Atkinson has identified three main characteristics of SE: relativity (i.e. exclusion is relative to a particular society); agency (i.e. they are excluded as a result of the action of an agent or agents); and dynamics (meaning that future prospects are relevant as well as current circumstances) (see Atkinson, 1998; Micklewright, 2002). Room (1999) concurs with the relational and dynamic aspects and adds three others: the multidimensionality of SE; a neighbourhood dimension (i.e. that deficient or absent communal facilities are in question); and that major discontinuities are involved.

The dynamic focus and an emphasis on the processes that engender deprivation are distinguishing features of this approach, compared to the approaches reviewed earlier. It has been noted, for example, that $\mathrm{SE}$ is “... a dynamic process, best described as descending levels: some disadvantages lead to some exclusion, which in turn leads to more disadvantages and more exclusion and ends up with persistent multiple (deprivation) disadvantages" (Eurostat Taskforce, 1998, p. 25). While the other approaches can study causes and interconnections between different elements of deprivation, such investigation is not part of the process of identifying the poor. In contrast, the definition of SE typically includes the process of becoming poor as well as some outcomes of deprivation.

SE also contrasts with the two previous approaches in making a social perspective central - that is to say SE is socially defined, and is often a characteristic of groups (the aged, handicapped, racial or ethnic categories) rather than pertaining to individuals. This relational emphasis opens up a different policy agenda from the individualistic approaches, e.g. policies addressed to groups, such as eliminating discrimination and various forms of affirmative action. While other approaches can be extended to include these considerations, such as the recent developments in the studies of vulnerability in a monetary perspective, $\mathrm{SE}$ is the only approach where these considerations play a constitutive role.

Multidimensionality is an intrinsic feature of SE. Indeed, being deprived in more than one, and perhaps many, dimensions is a key feature of SE, which raises aggregation issues similar to those of CA. ${ }^{18}$ Furthermore, empirical work points to causal connections between different dimensions of exclusion, e.g. between: employment and income; housing and employment; formal sector employment and insurance. SE generally is found to have a strong connection with monetary poverty. For example, lack of monetary income is both an outcome of SE (arising from lack of employment) and a cause (e.g. of social isolation and low wealth).

In order to apply SE empirically to particular societies, these general statements about SE need to be interpreted more specifically. The precise characteristics of SE tend to be society-specific, since they identify exclusion from normal activities. The concept of SE thus necessarily involves a relative approach to the definition of poverty. In industrial countries the indicators adopted in empirical work normally include unemployment, access to housing, minimal income and social contacts, lack of citizenship or democratic rights.

The application of the concept of exclusion to developing countries raises difficult 
issues. Characteristics of SE are likely to be different from those in developed countries. On the one hand, the defining features noted by Atkinson and Room are clearly highly relevant. On the other hand, it is difficult to identify appropriate norms to provide the benchmarks of exclusion, since exclusion from formal sector employment or social insurance coverage tends to apply to the majority of the population. Lack of formal sector employment or social insurance coverage therefore does not imply exclusion from normal social patterns or relationships. To the extent that the normal may not be desirable, what is "normal" may not be satisfactory in defining the benchmarks of exclusion. Consequently, there is a serious problem in deciding what would be appropriate SE characteristics. A further complication is that exclusion, as with the caste system, is part of the social system in some societies. Various solutions to the interpretation of SE in particular societies are possible: one is to take norms from outside the society, say from developed countries. Some work on the marginalization of societies in the process of globalization implicitly does just that (Room, 1999). Another is to derive the characteristics through consultation in participatory approaches. A third approach is to derive the characteristics empirically, by exploring what structural characteristics of a population (such as race, or caste, or region) are empirically correlated with multiple deprivations identified in other approaches.

Empirical work in developing countries has adopted a variety of approaches to the definition of SE. It mostly takes definitions that seem relevant to the reality being studied, without providing much justification for their particular choice and rarely making any explicit reference to what is actually normal in the society. For example:

(1) A study in India (Appasamy et al., 1996) defines SE as exclusion from health services, education, housing, water supply, sanitation and social security. This broad definition picks up very large numbers of people as being socially excluded.

(2) In Venezuela, Cartaya et al. (1997) first define social and political rights and then interpret $\mathrm{SE}$ as not having these rights.

(3) A study of Tanzania identifies certain very poor urban occupations and the rural landless as excluded (Rodgers et al., 1995).

(4) An ILO study in Tunisia used the perceptions of various groups to define social exclusion-the different groups produced different characteristics: the authors concluded that social integration required employment and a guaranteed source of income (Bedoui \& Gouia, 1995).

(5) In Cameroon and Thailand, ethnic minorities have been defined as being excluded, given the prevalent reconstruction of citizenship. In the case of Thailand, other categories also included were poorly educated farmers, informal sector workers and the homeless (Rodgers et al., 1995).

3.3.1 Some conclusions on SE. SE is perhaps the least well-defined and most difficult to interpret of the concepts of deprivation under review. Indeed, according to Micklewright (2002, p. 7), "exclusion is a concept that defies clear definition and measurement". Problems of definition are especially great in applying the concept to developing countries because "normality" is particularly difficult to define in multipolar societies, and because there can be a conflict between what is normal and what is desirable. The question of whether there exist relevant discontinuities also arises in a particularly difficult form, since the characteristics defining SE are society-specific and researchers in each country need to devise their own methods for identifying dimensions and appropriate breaks. 
None the less, the approach is the only one that focuses intrinsically, rather than as an add-on, on the processes and dynamics that allow deprivation to arise and persist. Moreover, the analysis of exclusion lends itself to the study of structural characteristics of society and the situation of groups (e.g. ethnic minorities or the landless) that can generate and characterise exclusion, whereas the two individualistic approaches (the monetary and CA) tend rather to focus on individual characteristics and circumstances. $\mathrm{SE}$ also leads to a focus on distributional issues - the situation of those deprived relative to the norm generally cannot improve without some redistribution of opportunities and outcomes - whereas monetary poverty (defined in absolute terms) and capability poverty can be reduced through growth without redistribution. The agency aspect of SE, noted by Atkinson, also points to excluders as well as excludees, with the main responsibility for improving the situation on the former, again a contrast to the monetary and capability approaches that describe a world without analysing or attributing responsibility.

\subsection{Participatory Methods}

Conventional poverty estimates, including both monetary and capability estimates, have been criticized for being externally imposed, and for not taking into account the views of poor people themselves. The participatory approach-pioneered by Chambers-aims to change this and to get people themselves to participate in decisions about what it means to be poor and the magnitude of poverty (Chambers, 1994, 1997). The practice of participatory poverty assessments (PPA) evolved from participatory rural appraisal (PRA), defined as "a growing family of approaches and methods to enable local people to share, enhance and analyse their knowledge of life and conditions, to plan and to act" (Chambers, 1994, p. 57).

Initially intended for small projects, PPA were scaled up by the World Bank as a complement to their poverty assessments. By 1998 half the completed World Bank poverty assessments included a participatory element. An extensive multi-country exercise (23 countries) was also carried out as background to the World Bank 2000/01 World Development Report, published as Voices of the Poor (Narayan-Parker \& Patel, 2000). Poverty Reduction Strategy Papers (PRSPs) of the World Bank and IMF, which form an important element in World Bank and IMF lending to poor countries, have further institutionalized the use of participatory methods. ${ }^{19}$

Cornwall (2000) differentiates three types of PA:

(1) those associated with self-determination and empowerment;

(2) those associated with increasing the efficiency of programmes;

(3) those emphasizing mutual learning.

The use of participatory exercises by the World Bank, especially in their poverty assessments, has tended to be instrumental, adopting PPA primarily so that the poor would co-operate with the programmes rather than to change the nature of the programmes themselves (type 2), while Voices of the Poor emphasizes type 3. There is little of self-determination and empowerment in most of this work.

3.4.1 Method and tools. Contextual methods of analysis are involved, i.e. data collection methods that "attempt to understand poverty dimensions within the social, cultural, economic and political environment of a locality" (Booth et al., 1998, p. 52). The 
Table 2. Elements of a PRA in Zambia

\begin{tabular}{ll}
\hline Issues & Methods \\
\hline $\begin{array}{l}\text { Perceptions and indicators of wealth, } \\
\text { well-being and poverty }\end{array}$ & Wealth/well-being grouping \\
& $\begin{array}{l}\text { Social mapping } \\
\text { Semi-structured mapping }\end{array}$ \\
Assets of rural communities- & Resource mapping \\
including access to services, common & Focus group discussion \\
property resources, other natural & Institutional diagramming \\
resources & (Venn/Chapati diagram) \\
Assets of rural households & Wealth ranking/grouping \\
& Livelihood analysis \\
Coping strategies in times of crisis & Livelihood analysis \\
& Semi-structured interviews \\
& Ranking exercises \\
Community-based support mechanisms & Institutional mapping \\
for the rural poor & Semi-structured interviews \\
Long-term environmental trends, e.g. & Historical transects \\
declining soil fertility, declining & Community time lines \\
rainfall & Resource mapping at different points in \\
& time \\
& Trend analysis \\
\hline
\end{tabular}

Source: de Graft Agyarko (1998) in IDS (1998).

methods derive from and emphasize poor people's ability to understand and analyse their own reality.

A range of tools has been devised, including the use of participatory mapping and modelling, seasonal calendars, wealth and well-being ranking. The large variety of methods can be used flexibly. This contrasts with the other approaches, where a more rigid framework and methodology is involved. Table 2 illustrates, drawing on elements of the approach adopted in a Zambian PRA.

3.4.2 Some challenges in truly operationalizing PPAs. In principle, people themselves conduct PPAs but inevitably it is nearly always outsiders who conduct the assessments and interpret the results. For example, Voices of the Poor identified five types of well-being-material, physical, security, freedom of choice and action, and social well-being, a classification which emerged at least partly from subsequent rationalization of the materials gathered in the various studies. An evaluation of PPAs in Africa noted that certain themes were not emphasized in the analysis, and many were omitted altogether. There was obvious "selectivity" due to pressures to highlight what were considered to be policy-relevant conclusions (Booth et al., 1998).

Although the participatory methods are intended to determine the nature of projects and elicit the views of poor people to shape plans and contribute to development strategies, in practice their impact on projects or plans is limited. For example, the PRSPs, prepared before debt relief can be agreed under HIPC (Highly Indebted Poor Countries Initiative), require participatory exercises as inputs. Yet 39 organizations and regional networks in 15 African countries agreed at a meeting in Kampala, May 2001, that PRSPs "were simply window-dressing". ${ }^{20}$ The statement concluded that "the PRSP process is simply delivering repackaged structural adjustment programmes and is not delivering poverty focused development plans and has failed to involve civil society and parliamentarians in economic policy discussions". The perceived lack of 
"scientificity" of the methods and their subjective nature, together with political economy considerations, undoubtedly contribute to this poor outcome.

A basic problem arises from heterogeneity in the community: the question, in that case, is whose voices are being heard. Where there are conflicts within a community, the PPA has no agreed way of resolving them to arrive at a single community view. Moreover, certain groups are likely to be fearful of voicing opposition to powerful members of the community. It has been argued that PPA tends to condone and reinforce existing social relations (da Cunha \& Junho Pena 1997). Furthermore, some people are structurally excluded from "communities". For example, groups often identify others outside the group as being really poor, and sometimes almost subhuman. These outsiders generally consist of people who no longer have social relations with the rest of the community, typically the poorest who have fallen through the cracks of the reciprocity network (Howard \& Milward (1997) provides poignant examples). The method, by focusing on "the community", whether real or perceived, does not compensate for such exclusions. Furthermore, the intensive process involved in participatory poverty assessment often means that only small numbers are included, who tend to be got together on an ad hoc basis and rarely constitute representative samples of the population.

There is a deeper problem about exclusive reliance on participatory methods, which goes back to Sen's criticisms of the utilitarian approach. People's own assessment of their own condition can overlook their objective condition and can be biased as a result of limited information and social conditioning (i.e. these methods also suffer from "valuation neglect"). The generally public aspect of assessments may also make it difficult to get honest assessments, and could involve participants in some risk.

3.4.3 Some conclusions on PPA. The major advantage of this approach is that PPAs largely get away from externally imposed standards. They also provide a way of solving some of the problems encountered with the other methods. For example, they help to define: an appropriate minimum basket of commodities for the monetary approach; a list of basic capabilities in the capability approach; and whether the concept of SE can be applied in a particular society and what its main elements might be.

There are two major differences from the other approaches. The main one is that the perspective is that of the poor, who, at least in theory, make the judgements which in other approaches are imposed from outside. The other is in the small samples-even in the scaled-up version-relative to other methods. It is therefore difficult to carry out statistical significance tests on material gathered in this way. The method is complex and invariably contains multidimensional analysis. Like the SE it includes processes, causes and outcomes of poverty, as perceived by the poor. The method is apparently cost-effective, but the community spends much more time on these exercises-estimated at five times more in one study (de Graft Agyarko, 1998)—which is not usually costed.

\subsection{A Comparative Overview}

Each of the approaches to poverty derives from a different perspective on what constitutes a good life and a just society. For operationalization, each requires methodological assumptions that are often not transparent. Because of the major differences in definition, who counts as poor is likely to differ according to the approach and the precise methods used by each approach. Moreover, the different approaches have 
different implications for policy, as considered below. Table 3 provides an overview of comparisons between the approaches, on a number of criteria discussed earlier.

Two important issues not discussed earlier are data availability and policy implications. Currently, for many countries data are available at regular intervals for the measurement of monetary poverty, from household consumer surveys and sometimes national income data. ${ }^{21}$ Moreover, the data are usually available on a continuum so it is possible to vary the poverty line and to measure the depth of poverty. In contrast, data for different types of capability poverty are often unavailable on a regular basis and rely on one-off surveys, with some capabilities not measured at all and others with deficient indicators. There are similar data deficiencies with respect to dimensions of social exclusion. These deficiencies reflect prior preoccupation with monetary poverty, not any intrinsic property of the data. Participatory data are different in this respect. By their nature they require intensive dialogue with groups of the poor, and are difficult to organize nationally or at short intervals. However, a modified form of consultation can be carried out comprehensively and regularly, along with other surveys.

From a policy perspective, the approach adopted has important implications:

- The use of a monetary concept suggests that the solution is generation of money incomes. The development of capabilities might also be recommended, but only instrumentally as a means of increasing productivity and hence money incomes among the poor.

- The use of the capability approach in general suggests emphasis on a wider range of mechanisms - the social provision of goods, improved allocation of goods within the family and the more efficient use of goods to achieve health, nutrition and education, as well as money income as a means for promoting basic capabilities.

- In this paper, basic capabilities have been interpreted in material terms, but potentially the approach can readily be extended to other spheres, such as political or cultural life. This is not the case with the monetary approach.

- Both monetary and capability approaches are fundamentally concerned with absolute poverty in most developing country contexts. Hence, one important policy response is to raise the level of the sea so that all boats may rise too ("Growth is good for the poor" as Dollar \& Kraay (2001) put it). Distributional issues are present but not at the forefront.

- In contrast, the relative element in poverty is at the forefront in the social exclusion approach. Indeed, for this it is unlikely that growth alone can ever eliminate social exclusion. Hence, redistributive polices and structural policies get priority.

- The monetary and capability approaches are essentially individualistic. Group features are consequently often ignored in policies, which tend to be focused on individual access to resources or transfers, and at best are regarded as instrumental. Yet in social exclusion particularly, and also to a considerable extent in participatory approaches, the prime focus is on group characteristics. For social exclusion, therefore, policies such as correcting racial discrimination, or class barriers, or citizenship restrictions, are likely to play a central role in defining policy priorities

\section{Some Empirical Evidence on the Approaches to Poverty Measurement}

A critical issue for our comparison is whether the four approaches identify broadly the same people as poor, as if they do the theoretical differences may be unimportant in policy or targeting terms. Despite its theoretical deficiencies, monetary poverty could be 
Table 3. A comparison of the four approaches to poverty

\begin{tabular}{|c|c|c|c|c|}
\hline & Monetary poverty & Capability approach & Social exclusion & $\begin{array}{l}\text { Participatory } \\
\text { approach }\end{array}$ \\
\hline Unit of analysis & $\begin{array}{l}\text { Ideally the individual, } \\
\text { de facto the household }\end{array}$ & The individual & $\begin{array}{l}\text { Individuals or groups } \\
\text { relative to others in their } \\
\text { community/society }\end{array}$ & $\begin{array}{l}\text { Groups and } \\
\text { individuals within } \\
\text { them }\end{array}$ \\
\hline $\begin{array}{l}\text { Required or } \\
\text { minimum standard } \\
\text { identified by }\end{array}$ & $\begin{array}{l}\text { Reference to 'external' } \\
\text { information (defined } \\
\text { outside the unit); } \\
\text { central element food } \\
\text { requirements }\end{array}$ & $\begin{array}{l}\text { Reference to 'lists' of } \\
\text { dimensions normally } \\
\text { assumed to be } \\
\text { objectively definable }\end{array}$ & $\begin{array}{l}\text { Reference to those } \\
\text { prevailing in society and } \\
\text { state obligations }\end{array}$ & $\begin{array}{l}\text { Local people's own } \\
\text { perceptions of well- } \\
\text { being and ill-being }\end{array}$ \\
\hline $\begin{array}{l}\text { Sensitivity to social } \\
\text { institutions }\end{array}$ & $\begin{array}{l}\text { None, but assessments } \\
\text { can be broken down } \\
\text { by group }\end{array}$ & $\begin{array}{l}\text { Emphasis on adequacy } \\
\text { rather than sufficiency } \\
\text { leaves space for (non- } \\
\text { modelled) variations }\end{array}$ & Central element & $\begin{array}{l}\text { Reflected in the } \\
\text { way poor people } \\
\text { analyses there own } \\
\text { reality }\end{array}$ \\
\hline $\begin{array}{l}\text { Importance of } \\
\text { processes }\end{array}$ & $\begin{array}{l}\text { Not essential } \\
\text { Increasing emphasis }\end{array}$ & Not clear & $\begin{array}{l}\text { One of the main thrusts } \\
\text { of the approach }\end{array}$ & $\begin{array}{l}\text { Critical for } \\
\text { achievement of } \\
\text { satisfactory } \\
\text { methods }\end{array}$ \\
\hline $\begin{array}{l}\text { Major weaknesses } \\
\text { conceptually }\end{array}$ & $\begin{array}{l}\text { Utility is not an } \\
\text { adequate measure of } \\
\text { well-being, and poverty } \\
\text { is not an economic } \\
\text { category }\end{array}$ & $\begin{array}{l}\text { Elements of } \\
\text { arbitrariness in choice } \\
\text { of basic capabilities, } \\
\text { problems of adding up }\end{array}$ & $\begin{array}{l}\text { Broad framework, } \\
\text { susceptable to many } \\
\text { interpretations, difficult } \\
\text { to compare across } \\
\text { countries }\end{array}$ & $\begin{array}{l}\text { Whose perceptions } \\
\text { are being elicited, } \\
\text { and how } \\
\text { representative or } \\
\text { consistent are they? } \\
\text { How does one deal } \\
\text { with diagreements? }\end{array}$ \\
\hline $\begin{array}{l}\text { Problems for cross- } \\
\text { country } \\
\text { comparisons }\end{array}$ & $\begin{array}{l}\text { Comparability of } \\
\text { surveys, of price } \\
\text { indices, of drawing } \\
\text { poverty lines }\end{array}$ & $\begin{array}{l}\text { Fewer problems if basic } \\
\text { capabilities are defined } \\
\text { externally, but adding- } \\
\text { up difficulties makes } \\
\text { comparisons difficult } \\
\text { with inconsistencies } \\
\text { according to adding-up } \\
\text { methodology }\end{array}$ & $\begin{array}{l}\text { Lines of social exclsion } \\
\text { essentially society- } \\
\text { specific; also an adding- } \\
\text { up problem }\end{array}$ & $\begin{array}{l}\text { Cultural difference } \\
\text { can make } \\
\text { appropriate } \\
\text { processes differ } \\
\text { across societies, } \\
\text { result may not be } \\
\text { comparable }\end{array}$ \\
\hline Data availability & $\begin{array}{l}\text { Household surveys } \\
\text { regularly conducted; } \\
\text { omitted observations } \\
\text { can be important. } \\
\text { Use of national income } \\
\text { data-but requires } \\
\text { assumptions about } \\
\text { distribution }\end{array}$ & $\begin{array}{l}\text { Data less regularly } \\
\text { collected, but could } \\
\text { easily be improved }\end{array}$ & $\begin{array}{l}\text { Currently have to rely } \\
\text { on data collected for } \\
\text { other purposes. If } \\
\text { agreed on basic } \\
\text { dimensions, data } \\
\text { could be regularly } \\
\text { collected }\end{array}$ & $\begin{array}{l}\text { Generally only } \\
\text { small purposive } \\
\text { samples. Never } \\
\text { available nationally, } \\
\text { would be difficult to } \\
\text { extend method for } \\
\text { regular national } \\
\text { data collection }\end{array}$ \\
\hline $\begin{array}{l}\text { Major weaknesses } \\
\text { for measurement }\end{array}$ & $\begin{array}{l}\text { Needs to be anchored } \\
\text { to external elements } \\
\text { Arbitrary }\end{array}$ & $\begin{array}{l}\text { Impossibility of set } \\
\text { evaulation. How to deal } \\
\text { with } \\
\text { multidimensionality } \\
\text { even if only of basic } \\
\text { functionings }\end{array}$ & $\begin{array}{l}\text { Problems with } \\
\text { multidimensionality } \\
\text { Challenge of capturing } \\
\text { process }\end{array}$ & $\begin{array}{l}\text { How comparable? } \\
\text { How } \\
\text { representative? }\end{array}$ \\
\hline $\begin{array}{l}\text { Interpreted by } \\
\text { policy-makers as } \\
\text { requiring }\end{array}$ & $\begin{array}{l}\text { Emphasis on } \\
\text { economic growth and } \\
\text { distribution of } \\
\text { monetary income }\end{array}$ & $\begin{array}{l}\text { Investments in extending } \\
\text { basic capabilties/basic } \\
\text { needs via monetary } \\
\text { incomes and public } \\
\text { services }\end{array}$ & $\begin{array}{l}\text { Foster processes of } \\
\text { inclusion, inclusion in } \\
\text { markets and social } \\
\text { process, with particular } \\
\text { emphasis on formal } \\
\text { labour market }\end{array}$ & $\begin{array}{l}\text { Empowerment of } \\
\text { the poor }\end{array}$ \\
\hline
\end{tabular}


used as a proxy for other types of poverty if broadly the same people are identified as poor under the different measures.

In any empirical comparison it first has to be decided how the particular approach is to be used, solving many of the difficult issues discussed above. In the comparisons we adopt, we try and use commonly assumed solutions to these issues, since the aim is to explore differences that occur in practice when alternative methods are used.

For countries as a whole and for regions of the world, it appears that poverty rates differ significantly according to the approach adopted. Table 4 shows that country ranking differs in comparing capability poverty and both international and national monetary poverty lines. ${ }^{22}$ As shown by Figures 3 and $4,{ }^{23}$ at the country level different measures of deprivation are associated, and indeed one cannot reject the hypothesis that the different measures are not independent. What is striking, however, is that low levels of poverty according to one measure are compatible with high levels of poverty according to another. It is this variability which points to the potential lack of overlap in practice between different ways of measuring poverty, and it is this variability which calls for in-depth empirical assessment of the underlying causes. Such empirical tests can also show whether different measures are capturing different populations.

A study of India and Peru, drawing on both national data sets and micro-surveys, found that significantly different people ${ }^{24}$ were identified as poor in the two countries according to whether the monetary, capability or participatory approach was adopted. ${ }^{25}$

The national data sets showed that in India, using the national poverty line, monetary poverty, at $38 \%$, was below capability poverty: $52 \%$ of adults were education poor (illiterate); and $26 \%$ of children were education poor (not attending primary school); $70 \%$ of children less than 13 years old were undernourished, $44 \%$ severely; but only $7 \%$ of individuals between 7 and 59 suffered from chronic illness.

In Peru, in contrast, monetary poverty at $54 \%$ (again using a national poverty line) was greater than capability poverty: $20 \%$ of the adults and $7 \%$ of the children were education poor; $10 \%$ of adults were health poor and $29 \%$ of the children below 5 years were undernourished.

The extent of the lack of overlap in individuals falling into monetary and capability poverty is shown in Table 5 .

For example:

- In India, $43 \%$ of children and over half of adults who were capability poor, using education or health as the indicator, were not in monetary poverty; similarly, over half the nutrition poor children were not in monetary poverty.

- In Peru, around one-third of children and adults who were education-capability poor were not monetary poor; while one-fifth of children and over half of adults who were capability poor (health/nutrition) were not monetary poor.

Are the large proportions of individuals who are monetary poor but not capability poor, or conversely, an artefact of the particular poverty lines selected? An investigation of the extent of capability poverty for different monetary deciles shows that altering the monetary poverty line would not greatly alter the results. For example, in India, although levels of education poverty were lower in higher deciles, 33\% of the richest tenth of the population were illiterate (compared with $64 \%$ among the lowest decile). The proportion of health poor in the highest decile is quite similar to that in the lowest decile. Among those with incomes even as high as the seventh monetary decile more than $50 \%$ are poor in either education or health. In Peru, $12 \%$ of the top decile are education poor among adults, and 5\% among children-compared with $32 \%$ in the lowest decile for adults and $9 \%$ for children. The incidence of child undernutrition is 
Monetary poverty (national line) and capability poverty (HPI) late 1990s

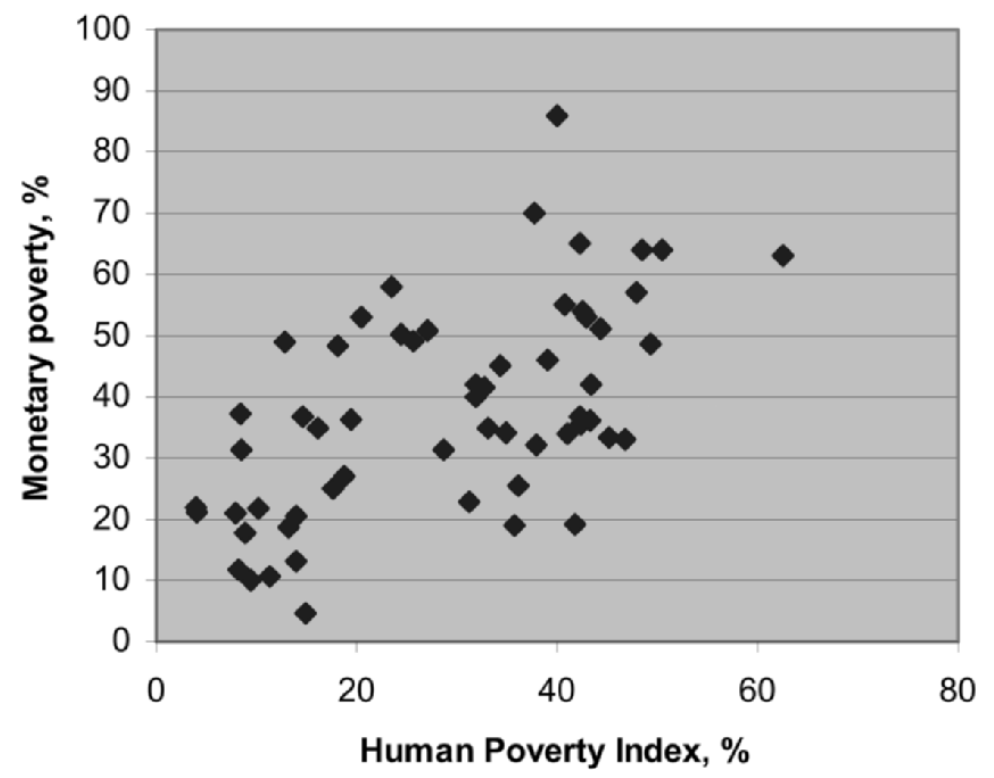

Figure 3. World poverty.

\section{Monetary poverty ( $\$ 1$ a day) and capability poverty (HPI) late 1990 s}

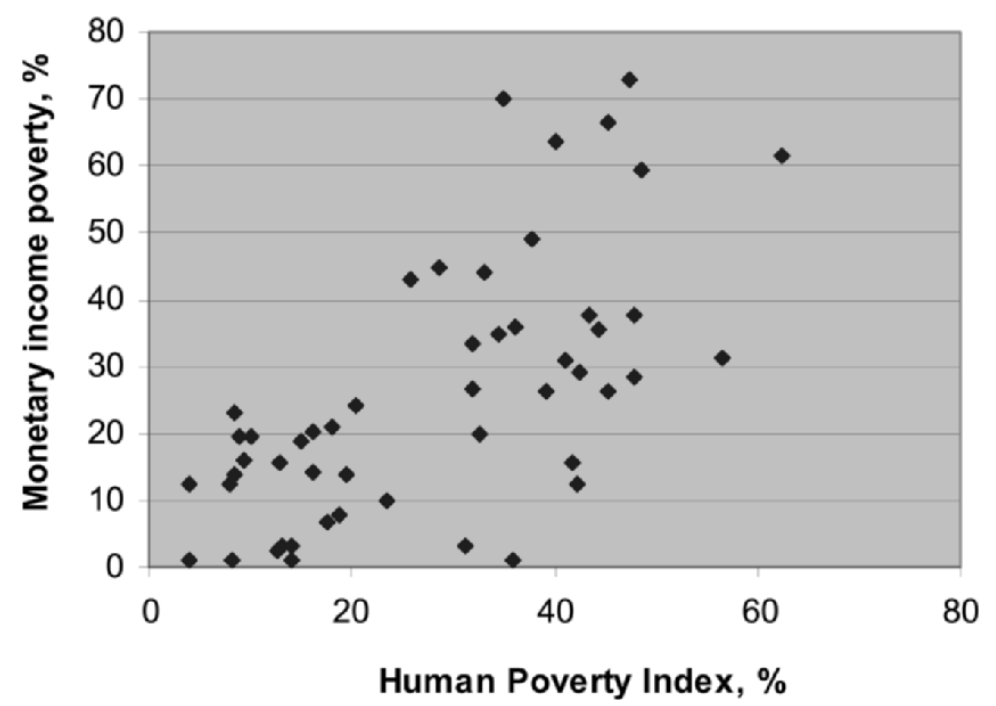

Figure 4. 
Table 4. Monetary and capability poverty compared—selected countries $\%$ of population in poverty

\begin{tabular}{lcccccr}
\hline & $\begin{array}{c}\text { HPI } \\
\text { (HDR }\end{array}$ & Rank & $\begin{array}{c}\text { International } \\
\text { monetary poverty } \\
1983-2000\end{array}$ & Rank & $\begin{array}{c}\text { National } \\
\text { poverty line } \\
1978-2000\end{array}$ & Rank \\
\hline Costa Rica & 4.0 & 1 & 12.6 & 4 & 22.0 & 5 \\
Chile & 4.1 & 2 & $<2$ & 1 & 21.2 & 4 \\
Mexico & 9.4 & 3 & 15.9 & 6 & 10.1 & 2 \\
Peru & 12.8 & 4 & 15.5 & 5 & 49.0 & 9 \\
Sri Lanka & 17.6 & 5 & 6.6 & 3 & 25.0 & 7 \\
China & 14.9 & 6 & 18.8 & 7 & 4.6 & 1 \\
Egypt & 31.2 & 7 & 3.1 & 3 & 22.9 & 6 \\
India & 33.1 & 8 & 44.2 & 10 & 35.0 & 10 \\
Morocco & 35.8 & 9 & $<2$ & 1 & 19.0 & 3 \\
Zimbabwe & 36.1 & 10 & 36.0 & 9 & 25.5 & 8 \\
Uganda & 40.8 & 11 & n.a. & n.a. & 55.0 & 11 \\
Ethiopia & 56.5 & 12 & 31.2 & 8 & n.a. & n.a. \\
\hline
\end{tabular}

${ }^{a}$ Human poverty index $(\mathrm{HPI})=$ geometric average of percentage of people not expected to live to 40 years; adult illiteracy rate; and average lack of access to safe water and sanitation.

${ }^{\mathrm{b}}$ Monetary poverty $=$ percentage of population with less than one dollar a day, valued at purchasing power parity.n.a., not available.

Source: UNDP (2002).

$5 \%$ for the top decile of money incomes compared with $9 \%$ for the lowest decile. Hence changing the cut-off line for monetary poverty would not eliminate the weak overlaps with capability poverty in either country.

Micro-studies permitted a comparison of poverty magnitudes according to the capability and monetary approaches, and also using participatory methods. Again, big differences were apparent.

- In India, in the urban areas only around half of those ranked as "low well-being" by participatory methods were also monetarily poor. ${ }^{26}$ Even the highest monetary decile had $34 \%$ of individuals ranked "low well-being". In Peru, in the rural area, $48 \%$ of the monetary non-poor were identified as poor according to the well-being ranking, while $39 \%$ of the extremely poor, by well-being ranking, were not monetary poor. In the urban area, $49 \%$ of the monetary non-poor were ranked as poor while $44 \%$ of those ranked as poor were not monetary poor.

- In Peru, a lack of overlap also showed between self-perceptions of poverty and monetary poverty. In the rural area, $29 \%$ of the self-declared poor were non-poor according to the monetary indicator, while of the monetary poor, $42 \%$ did not believe themselves to be poor. In the urban area, $40 \%$ of the self-declared poor were not monetary poor, and $42 \%$ of the monetary poor did not state that they were poor.

The India/Peru study had problems in estimating social exclusion. It had been intended that the participatory focus groups would define social exclusion, and this definition would then be applied to the data set. But none of the participatory activities generated a definition of social exclusion-none of the groups saw themselves as socially excluded. In India, even those belonging to the lower castes, while aware of boundaries with upper castes, did not consider themselves as socially excluded. The study, therefore, did not generate a good definition of social exclusion for these societies. In India, however, a rural group suggested the concept of "social boycott" to describe a 
Table 5. Lack of overlaps between monetary and CA poverty

\begin{tabular}{lllllll}
\hline \multirow{2}{*}{$\begin{array}{l}\text { Capability poverty } \\
\text { measured as }\end{array}$} & & \multicolumn{2}{c}{ Education } & & \multicolumn{2}{c}{ Nutrition/health } \\
\cline { 3 - 3 } \cline { 5 - 6 } \cline { 5 - 6 } \% of CA poor not in & India & 43 & 60 & & 53 & 63 \\
monetary poverty: & Peru & 32 & 37 & & 21 & 55 \\
\% of monetary poor & India & 65 & 38 & & 53 & 91 \\
not CA poor: & Peru & 93 & 73 & & 66 & 94 \\
\hline
\end{tabular}

Source: Franco et al. (2002).

(very few) individuals who were no longer socially accepted by local people. The two reasons for such a boycott were mixed marriage (across religions or castes) and suffering from leprosy.

Although Franco et al. were unable to identify social exclusion from participatory methods, the analysis of the incidence of different types of poverty pointed to certain groups as being particularly vulnerable to different types of poverty. In India these were people belonging to scheduled castes or tribes. For Peru, in rural areas, they were the landless and those speaking local languages, not Spanish; and, in the urban areas, those having only precarious (or no) employment.

The evidence from India and Peru thus points to significantly different populations identified as poor according to the different approaches. The findings of substantially different distributions of people in monetary and capability poverty have been paralleled in research on Chile and Vietnam (Ruggeri Laderchi, 1997; Baulch \& Masset, 2003) and by earlier work on Peru using different indicators (Ruggeri Laderchi, 2001a). In Uganda, participatory assessments of changes in poverty over time have differed from the monetary approach even over the direction of change (McGee, 2000). These large discrepancies in those defined as poor according to different methods mean that one cannot rely on a monetary indicator to identify those in other types of poverty, nor conversely. Consequently, theoretical differences between the various methods have serious practical implications for policy-making.

\section{Conclusions}

This review of the different approaches to the identification and measurement of poverty makes clear that there is no unique or "objective" way of defining and measuring poverty. There is a large element of "construction" involved in each of the poverty measures-by outsiders in the monetary, capability and SE approaches and by a combination of outsiders and the people themselves in PPA. All definitions of poverty contain some arbitrary and subjective elements, often imposed by the outside observer. But this is of most concern with respect to conceptualization and measurement in the monetary approach, since it gives the false impression of being the most accurate and objective of the methods, while the judgements made in order to arrive at a measure of monetary poverty are generally not apparent. The limited empirical consistency of the monetary approach with the capability approach poses particular problems since it means that monetary poverty does not consistently point to failure to achieve certain material objectives, such as adequate nutrition. In contrast, capability poverty-albeit also subject to relatively arbitrary decisions-transparently means that people are unable to function in some ways that are universally accepted as important for human 
development. Capability poverty may not amount to everything we think we mean by poverty, but it definitely constitutes part of it, and the more one extends the basic capabilities included, the greater the range of deprivations covered. While participatory methods have a lot to offer when applied to poverty analysis, both in helping to make methodological decisions with respect to the other methods and in providing a valuable (but not exclusive) definition of poverty, as perceived by the poor themselves, they should not be the exclusive approach as the perceptions of the poor (and even more the expression of these perceptions) can be conditioned by their circumstances.

A focus on measuring individual deprivation, whether it is monetary or capability, can neglect or even draw attention away from the fundamental causes of deprivation. In this respect the SE approach is particularly relevant. While we have found social exclusion difficult to define in the developing country context, we believe the effort to do so is important because it points to processes of impoverishment, structural characteristics of societies responsible for deprivation and group issues that tend to be neglected in other approaches.

Conceptualization, definitions and measurement have important implications for targeting and policy. The considerable lack of overlaps between the different approaches means that targeting according to one type of poverty will involve serious targeting errors in relation to other types. Moreover, definitions also have implications for policy. While a monetary approach suggests a focus on increasing money incomes (by economic growth, or redistribution), a capability approach tends to lead to more emphasis on the provision of public goods. Social exclusion draws attention to the need to break down exclusionary factors, for example, by redistribution and antidiscrimination policies. Thus, awareness of the conceptual apparatus underlying different practices, particularly in the case of the dominating paradigm of monetary poverty, is needed when adopting them. Furthermore, it suggests that identification and targeting of the poor with combined methods should be more widely adopted, reflecting the concerns for a broad characterization of poverty which are currently part of the development discourse.

Definitions do matter. Clearer and more transparent definitions of poverty are an essential prerequisite of any development policy that puts poverty reduction at its centre.

\section{Notes}

1. Of course, poverty has not always been the prime concern of the "development community". In the 1950s and 1960s, the main objective was economic growth. Recognizing that growth alone had not eliminated poverty, a series of poverty-reducing strategies was adopted in the 1970 s, including basic needs strategies. But these concerns were again forgotten in the 1980s when stabilization and adjustment policies and the advance of the market dominated official discourse and policies. The poor economic performance and sharp rise in poverty in many countries in the 1980s led to renewed interest in poverty. Following UNICEF's Adjustment with a Human Face in 1987(Cornia et al., 1987), UNDP's first Human Development Report in 1990 and the World Bank's 1990 World Development Report on poverty, poverty reduction once more became central to the development agenda. In the early 1990s, the World Bank President, Lewis Preston, declared that "poverty is the benchmark against which we must be judged".

2. This threefold classification is adopted by Ruggeri Laderchi (2001a) to compare the capability and the monetary approach in detail.

3. See Silver (1994) for a discussion of how societal characteristics translate into different definitions of social exclusion. 
4. For example, scaling household resources according to household composition to take into account different needs of different types of household members, as well as the possibility of enjoying economies of scales in consumption or using market prices to compare quantities over space and time

5. These two arguments have been amply discussed in the literature (see Sen (1993) for a summary of the main arguments) and will not be illustrated further here.

6. An early example of how this approach could lead to different estimates of poverty than those that correspond to other concerns was noted above: in the 19th Century the poor relief standards led to a poverty rate of just $5 \%$, while Booth and Rowntree came up with estimates of around $30 \%$.

7. Clarke and Qizilbash use "fuzzy" multidimensional measures. Chiappero-Martinetti (2000) and Cheli and Lemmi (1995) uses fuzzy measures in the context of the capability approach.

8. The Foster-Greer-Thorbecke formula is

$P_{\alpha}=\frac{1}{n} \sum_{i=1}^{q}\left(\frac{z-y_{i}}{z}\right)^{\alpha}$,

where $P_{\alpha}$ is the poverty index for value $\alpha$ which is the weight given to the depth of poverty, $n$ the total number of individuals in society, $q$ the number below the poverty line, $z$ the poverty line and $y_{i}$ the income of the $i$ th individual Foster et al. (1984).

9. A value of alpha equal to zero corresponds to the headcount ratio, or the percentage of individuals living in poverty, capturing the incidence of poverty; a value of alpha equal to one is the income gap index, and is therefore sensitive to the depth of poverty; a value of alpha equal to two, which is commonly used, is more sensitive to the severity of poverty.

10. Alternative reconstructions of utility such as a simple description of preferences undermine the ethical basis of utility for policy-making (see Sugden, 1993).

11. See Alkire (2002, chapter 5) for a discussion of similarities and differences between the BN and basic capability approaches.

12. A particular problem in this context is provided by the existence of other objectives that might either be deemed irrelevant for the assessment at hand, or might be hard to measure, whose relation with the dimensions of interest is unknown. Consider, for example, the case of a malnourished individual who might be fasting but "scoring high" in terms of the capability to lead a life that respects religious principles, versus an individual who is starved and does not have the option to be better nourished.

13. UNDP (2001), Human Development Report 2001. New York, United Nations. There have been minor changes in the constituent elements of both HPI-1 (human poverty among developing countries) and HPI-2 (human poverty among developed countries) since the initiation of the HPI in 1997.

14. Brandolini \& D'Alessio (1998) provide a comprehensive review of different aggregation strategies and the trade-off between obtaining complete orderings and imposing structure in the aggregation.

15. Clark and Qizilbash adopt a union approach in which anyone who is "core" deprived in any "core" dimension is considered to be poor.

16. The first use of the term, SE, has been attributed to Lenoir, French Secretary of State for Social Action in Government in 1974, referring to people who did not fit into the norms of industrial societies, were not protected by social insurance and were considered social misfits. It included the handicapped, drug users, delinquents and the aged, among others, and was estimated to account for one-tenth of the French population.

17. At an early meeting of the Centre for the Analysis of Social Exclusion at the London School of Economics (see Burchardt et al., 1999, p. 229).

18. Some empirical work in the UK, however, indicated that a relatively low proportion of people excluded on one dimension were also excluded on more than one other dimension. For example, of those without production activity, almost $40 \%$ also had low income, but less than one-fifth were politically disengaged or socially isolated (Burchardt et al., 1999, p. 237).

19. PRSPs are prepared by the member countries through a participatory process involving domestic stakeholders as well as external development partners, including the World Bank and International Monetary Fund (IMF web site, 29 January 2003).

20. "PRSPS are just PR say civil society groups", http://www.BrettonWoods project.org/topic/ adjustment/a23prspsstats.html.

21. There are severe disadvantages to the use of national income data-an assumption about the distribution of income is required to derive poverty lines (see Deaton, 2002). 
22. The Spearman rank correlation coefficient between the proportion of people according to the human poverty index and the proportion according to the international poverty line is 0.5 ; the rank correlation coefficient between human poverty and poverty estimates adopting national poverty lines is 0.47 .

23. Data for international poverty cover a range of years from 1983 to 2000 and that for national poverty lines from 1987 to 2000; all the data including those for the human poverty index, which is derived from data for 1995-2000, come from UNDP (2002, table 3).

24. There were significant distributional differences between monetary and capability poverty in each country, as signified by low levels of Cramer's V.

25. In this study national poverty lines were used for monetary poverty; capability poverty was interpreted as not being at school (for children) and illiteracy for adults; and health poverty was interpreted as under-nutrition, for children, and self-reported chronic illness for adults.

26. For India, for the participatory data comparisons involving the monetary approach could only be done on urban data due to problems with estimation of home-grown consumption in rural areas.

\section{References}

Alkire, S. (2002) Valuing Freedoms: Sen's Capability Approach and Poverty Reduction (Oxford, Oxford University Press).

Anand, S., Harris, C.J. \& Linton, O.B. (1993) On the Concept of Ultra-poverty, Centre for Population and Development Studies, Working Paper No. 93.02, Harvard University, June.

Appasamy, P., Guhan, S. \& Hema, R. (1996) Social exclusion from a welfare perspective (Geneva, International Institute for Labour Studies), Vol. x, p. 133.

Atkinson, A.B. (1989) Poverty and Social Security (London, Harvester Wheatsheaf).

Atkinson, A.B. (1998) Social exclusion, poverty and unemployment, in: A.B. Atkinson \& J. Hills (Eds) Exclusion, Employment and Opportunity, CASE Paper 4 (London, London School of Economics, Centre for Analysis of Social Exclusion).

Atkinson, A.B. \& Bourguignon, F. (1987) Income distribution and differences in needs, in: G. Feiwel (Ed.) Arrow and the Foundations of the Theory of Economic Policy (London, Macmillan), pp. 350-370.

Baker, J.L. (1997) Poverty Reduction and Human Development in the Caribbean: A Cross-country Study (Washington, DC, World Bank), p. 206.

Banks, J. \& Johnson, P. (1993) Children and Household Living Standards (London, Institute for Fiscal Studies).

Barry, B. (1998) Social Exclusion, Social Isolation and the Distribution of Income, CASE Paper 12 (London, London School of Economics, Centre for Analysis of Social Exclusion).

Baulch, B. \& Masset, E. (2003) Do monetary and non-monetary indicators tell the same story about chronic poverty? A study of Vietnam in the 1990s, World Development, 31, pp. 441-453.

Bedoui, M. \& Gouia, R. (1995) Patterns and processes of social exclusion in Tunisia, in: G. Rodgers, C. Gore \& J. Figueiredo (Eds) Social Exclusion: Rhetoric, Reality, Responses (Geneva, Institute for Labour Studies).

Booth, C. (1887) The inhabitants of Tower Hamlets (School Board Division), their condition and occupations, Fournal of the Royal Statistical Society, 50, pp. 326-340.

Booth, D., Holland, J., Hentschel, J., Lanjouw, P. \& Herbert, A. (1998) Participation and Combined Methods in African Poverty Assessments: Renewing the Agenda (London, DFID Social Development Division Africa Division).

Bourguignon, F. \& Chakravarty, S.R. (forthcoming) The measurement of multidimensional poverty, Fournal of Economic Inequality.

Brandolini, A. \& D’Alessio, G. (1998) Measuring Well-being in the Functioning Space, Banco d'Italia Reseach Department, mimeo.

Burchardt, T., Grand, J. Le \& Piachard, D. (1999) Social exclusion in Britain 1991-1995, Social Policy and Administration, 33, pp. 227-244.

Cartaya, V., Magallanes, R. \& Dominiquez, C. (1997) Venezuela: Exclusion and Integration, A Synthesis in the Building? (Geneva, International Institute of Labour).

Chambers, R. (1994) The origins and practice of PRA, World Development, 22, No. 7, pp. 953-969.

Chambers, R. (1997) Whose Reality Counts? Putting the First Last (London, Intermediate Technology Publications). 
Cheli, B. \& Lemmi, A. (1995) A "totally" fuzzy and relative approach to the multidimensional analysis of poverty, Economic Notes, 24, pp. 115-134.

Chiappero-Martinetti, E. (2000) A multidimensional assessment of well-being based on Sen's functioning theory, Rivista Internazionale di Scienze Sociali, CVIII, pp. 207-231.

Clark, D.A. \& Qizilbash, M. (2002) Core poverty and extreme vulnerability in South Africa, IARIW Conference, Djurhamn, Sweden, August.

Clert, C. (1999) Evaluating the concept of social exclusion in development discourse, European fournal of Development research, 11, pp. 166-199.

Cornia, G.A., Jolly, R. \& Stewart, F. (1987) Adjustment with a Human Face (Oxford, Oxford University Press).

Cornwall, A. (2000) Beneficiary, consumer, citizen perspectives on participation for poverty reduction, Institute of Development Studies, Sussex University.

Cunha, P.V. da \& Junho Pena, M.V. (1997) The Limits and Merits of Participation (Washington, DC, World Bank).

Dasgupta, P. (1993) An Enquiry into Well-being and Destitution (Oxford, Oxford University Press).

Deaton, A. (1997) The Analysis of Household Surveys: A Microeconometric Approach to Development Policy (Washington, DC, Johns Hopkins University Press, World Bank).

Deaton, A. (2002) Background paper for the UNDP Human Development Report (New York, UNDP).

Desai, M. (1995) Poverty and capability: towards an empirically implementable measure, in: $M$. Desai (Ed.) Poverty, Famine and Economic Development: The Selected Essays of Meghnad Desai, Vol. II (Aldershot, Edward Elgar), pp. 185-204.

Dhatt, G. \& Ravallion, M. (1998) Why have some Indian states done better than others at reducing rural poverty?, Economica, 65, pp. 17-38.

Dollar, D. \& Kraay, A. (2001) Growth is Good for the Poor (Washington, DC, World Bank,Policy Research Working Paper, 2587), p. 50.

Doyal, L. \& Gough, I. (1991) A Theory of Human Need (London, Macmillan Education).

Drèze, J. \& Sen, A.K. (1995) India: Economic Development and Social Opportunity (Delhi, Oxford University Press).

European Foundation (1995) Public Welfare Services and Social Exclusion: The Development of Consumer Oriented Initiatives in the European Union (Dublin, The European Foundation).

Eurostat Taskforce (1998) Recommendations on social exclusion and poverty statistics (Luxembourg, Eurostat).

Foster, J., Greer, J. \& Thorbecke, E. (1984) A class of decomposable poverty measures, Econometrica, 52, pp. 761-766.

Franco, S., Harriss-White, B., Ruggeri Laderchi, C. \& Stewart, F. (2002) Alternative realities? Different concepts of poverty their empirical consequences and policy implications, Queen Elizabeth House.

Graft Agyarko, R. de (1998) Influencing policy through poverty assessments: theoretical and practical overview of a changing process, PPA Topic Pack (IDS, Falmer, Brighton, Institute of Development Studies).

Grosh, M.E. \& Glewwe, P. (2000) Designing Household Survey Questionnaires for Developing Countries: Lessons from 15 years of the Living Standards Measurement Study (Washington, DC, World Bank).

Howard, M. \& Millard, A.V. (1997) Hunger and Shame: Poverty and Child Malnutrition on Mount Kilimanjaro (London, Routledge).

Hulme, D. \& Shepherd, A. (2003) Conceptualising chronic poverty, World Development, 31, pp. 403-423.

IDS (1998) PPA Topic Pack (Falmer, Brighton, Institute of Development Studies).

Lewis, G.W. \& Ulph, D.T. (1998) Poverty, inequality and welfare, The Economic Fournal, 98, pp. 117-131.

Lipton, M. (1988) The Poor and the Poorest. Some Interim Findings (Washington, DC, The World Bank).

Lipton, M. \& Ravallion, M. (1993) Poverty and Policy, World Bank, Policy Research Working Papers, WPS 1130 (Washington, DC, World Bank).

Marshall, T. (1981) The Right to Welfare, and Other Essays (London, Heinemann).

McGee, R. (2000) Analysis of Participatory Poverty Assessment (PPA) and Household Survey Findings on Poverty Trends in Uganda, Mission Report, 10-18 February.

Micklewright, J. (2002) Social Exclusion and Children: A European View for US Debate (Florence, UNICEF). 
Morduch, J. (1995) Income smoothing and consumption smoothing, fournal of Economic Perspectives, 9, No. 3, pp. 103-114.

Narayan-Parker, D. \& Patel, R. (2000) Voices of the Poor: Can Anyone Hear Us? (Oxford, Oxford University Press).

Nussbaum, M. (2000) Women and Human Development: A Study in Human Capabilities (Cambridge, Cambridge University Press).

Nussbaum, M.C., Sen, A.K. eds. (1993) The Quality of Life (Oxford, Clarendon Press).

Parijs, P. van (Ed.) (1992) Arguing for Basic Income: Ethical Foundations for a Radical Reform (London, Verso).

Payne, P.R. (1993) Undernutrition: measurement and implications, in: S. Osman (Ed.) Poverty, Undernutrition and Living Standards (Oxford, Clarendon Press).

Qizilbash, M. (1998) Poverty: Concept and Measurement (Islamabad, Sustainable Development Policy Institute).

Ravallion, M. (2002) How not to Count the Poor. A Reply to Reddy and Pogge (Washington, DC, World Bank).

Ravallion, M. (1998) Poverty Lines in Theory and Practice, LSMS Working Paper 133 (Washington, World Bank).

Reddy, S.G. \& Pogge, T.W. (2002) How not to Count the Poor (New York, Barnard College).

Rodgers, G., Gore, C. \& Figueiredo, J. (1995) Social Exclusion: Rhetoric, Reality, Responses (Geneva, Institute for Labour Studies).

Room, G. (1999) Social exclusion, solidarity and the challenge of globalisation, International Fournal of Social Welfare, 8, pp. 66-74.

Rowntree, B.S. (1902) Poverty. A Study of Town Life (London, MacMillan).

Ruggeri Laderchi, C. (1997) Poverty and its many dimensions: the role of income as an indicator, Oxford Development Studies, 25, pp. 345-360.

Ruggeri Laderchi, C. (2000) The Monetary Approach to Poverty: A Survey of Concepts and Methods, Working Paper 58, Oxford, Queen Elizabeth House.

Ruggeri Laderchi, C. (2001a) Do concepts of poverty matter? An empirical investigation of the differences between a capability and a monetary assessment of poverty in Peru, Doctoral Thesis, University of Oxford.

Ruggeri Laderchi, C. (2001b) Participatory Methods in the Analysis of Poverty: A Critical Review, Working Paper 62, Oxford, Queen Elizabeth House.

Saith, R. (2001a) Capabilities: The Concept and its Operationalisation, Working Paper 66, Oxford, Queen Elizabeth House.

Saith, R. (2001b) Social Exclusion: The Concept and Application to Developing Countries, Working Paper 72, Oxford, Queen Elizabeth House.

Sen, A.K. (1999) Development as Freedom (DAF) (Oxford, Oxford University Press).

Sen, A. (1997) On Economic Inequality, 2nd Edition (Oxford, Clarendon Press).

Sen, A.K. (1993) Capability and well-being, in: M.C. Nussbaum \& A.K. Sen (Eds) The Quality of Life (Oxford, Clarendon Press), pp. 30-53.

Sen, A.K. (1992) Inequality Reexamined (Cambridge, MA, Harvard University Press).

Sen, A.K. (1985) Commodities and Capabilities (Amsterdam, North-Holland).

Sen, A.K. (1976) Poverty: an ordinal approach to measurement, Econometrica, 44, pp. 219-231.

Sen, A.K. \& Foster, J. (1997) Inequality after a quarter century, in: A.K. Sen (Ed.) On Inequality, 2nd edn (Oxford, Clarendon Press).

Silver, H. (1994) Social Exclusion and Social Solidarity: Three Paradigms, IILS Discussion Papers, No 69, ILO, Geneva.

Stewart, F. (1995) Basic needs, capabilities and human development, Greek Economic Review, 17, pp. 83-96.

Stewart, F. (1985) Planning to Meet Basic Needs (London, Macmillan).

Streeten, P.P., Burki, S.J., ul Haq, M., Hicks, N. \& Stewart, F. (1981) First Things First, Meeting Basic Human Needs in Developing Countries (New York, Oxford University Press).

Sugden, R. (1993) Welfare, resources and capabilities: a review of "Inequality Re-examined" by Amartya Sen, Fournal of Economic Literature, 31.

Sukhatme, P.V. (Ed.) (1982) Newer Concepts in Nutrition and Their Implications for Policy (Pune, Maharashtra Associaiton for the Cultivation of Science).

Sukhatme, P.V. (1989) Nutritional adaptation and variability, European fournal of Clinical Nutrition, 43, pp. 75-87. 
Szekely, M., Lustig, N., Meijia, J.A. \& Cumpa, M. (2000) Do we know how much poverty there is? (Washington, DC, IADB).

Townsend, P. (1979) Poverty in the United Kingdom (London, Harmondsworth, Penguin). UNDP (1990) Human Development Report 1990 (New York, Oxford University Press). UNDP (1997) Human Development Report 1997 (New York, Oxford University Press). UNDP (2001) Human Development Report 2001 (New York, Oxford University Press). UNDP (2002) Human Development Report 2002 (New York, Oxford University Press). Wallace, M. (2001) Learning our lesson, The Big Issue.

World Bank (1990) World Development Report (Oxford, Oxford University Press). 
Copyright $\odot 2003$ EBSCO Publishing 